\title{
PERCEPÇÃO DO PAPEL DE PROFESSOR PARA PROFISSIONAIS DE EDUCAÇÃO FÍSICA RECÉM-FORMADOS ATUANTES EM ACADEMIAS DE GINÁSTICA
}

\author{
PERCEPTION OF THE PROFESSOR'S ROLE FOR NEWLY \\ TRAINED PHYSICAL EDUCATION PROFESSIONALS \\ ACTING IN GYMNASTICS ACADEMIES \\ PERCEPCIÓN DEL PAPEL DEL PROFESOR PARA LOS \\ PROFESIONALES DE EDUCACIÓN FÍSICA RECIÉN \\ GRADUADOS QUE TRABAJAN EN GIMNASIOS
}

\author{
Jỗo Vitor CRUZ \\ ROGÉRIO CRUZ DE OLIVEIRA ${ }^{\mathrm{I}}$ \\ 'Universidade Federal de São Paulo (UNIFESP), Santos/SP -Brasil
}

\begin{abstract}
RESUmo O objetivo do estudo consiste em compreender a percepção do papel de professor para profissionais de Educação Física recém-formados atuantes em academias de ginástica. A coleta de dados foi realizada através de uma entrevista semiestruturada versando sobre o papel do professor e o papel do professor em academias de ginástica, da qual participaram nove voluntários de ambos os sexos. A análise dos dados se deu por categorias não apriorísticas. Como resultado a percepção do papel de professor gravitou em torno de quatro categorias de análise: professor transmissor de conhecimento; professor influenciador; professor mediador do conhecimento, e; professor aprendiz. Quanto ao papel do professor em academias de ginástica tivemos outras quatro categorias de análise: conscientizador; acolhedor; instrutor; e; professor como aprendiz. Conclui-se que a percepção dos profissionais de Educação Física recém-formados em academias de ginástica sobre o seu papel como professor é múltipla, abrangendo desde perspectivas mais tradicionais até perspectivas mais críticas.
\end{abstract}

Palavras-chave: Práticas Corporais; Prática Pedagógica; Educação.

ABSTRaCr The aim of the study is to understand the perception of professor's role for recently undergraduate professionals of Physical Education working in gyms. Data collection was carried out through a semi-structured interview on the role of being a professor and the professor's role in gyms, in which nine volunteers of both sexes have participated. Data 
analysis was performed by non-a priori categories. As a result, the perception of professor's role gravitated around four categories of analysis: professor transmitting knowledge; influential professor; knowledge mediator professor, and; apprentice professor. As for the professor's role in gyms, we had four other categories of analysis: awareness; welcoming; instructor; and; professor as an apprentice. It is concluded that the perception of recently undergraduate professionals of Physical Education in gyms about their role as a professor is multiple, ranging from more traditional to more critical perspectives.

Keywords: Body Practices; Pedagogical Practice; Education.

RESUMÉN El objetivo del estudio es comprender la percepción del papel del profesor para los profesionales de educación física recién graduados que trabajan en gimnasios. La recopilación de datos se realizó a través de una entrevista semiestructurada sobre el papel de profesor y el papel del profesor en los gimnasios, en el que participaron nueve voluntarios de ambos sexos. El análisis de los datos se realizó por categorías no a priori. Como resultado, la percepción del papel de profesor gravitaba en torno a cuatro categorías de análisis: el profesor transmitía conocimiento; profesor influyente; profesor mediador de conocimiento, y; aprendiz de profesor. En cuanto al papel del profesor en los gimnasios, teníamos otras cuatro categorías de análisis: concienciador; acogedor técnico; y; profesor como aprendiz. Se concluye que la percepción de los profesionales de Educación Física recientemente graduados sobre su papel en los gimnasios como docentes es múltiple, desde perspectivas más tradicionales hasta perspectivas más críticas.

Palabras clave: Prácticas corporales; Práctica Pedagógica; Educación.

\section{INTRODUÇÃo}

Scherer (2005) afirma existir uma maior diversificação do campo de atuação do profissional de Educação Física nos últimos vinte anos. De acordo com o autor, isso decorre devido à hegemonia da visão a qual associa desenvolvimento profissional ao individualismo, funcionalismo e, sobretudo, a preocupação estética: marcas da sociedade capitalista atual.

Isso é percebido por Le Breton (2003) quando afirma a existência de uma supervalorização do corpo jovial que marginaliza os aspectos físicos da velhice como algo patológico na estética corporal vigente. Em resposta a essa demanda, surgem as academias de ginástica. Bertevello (2006) aponta crescimento quase que exponencial dessa instituição nesse período, abastando a crescente formação de profissionais da área.

De acordo com Furtado (2007), a emergência das academias de ginástica se concretiza por prometerem a estética como produto através do comércio das práticas corporais ${ }^{1}$ orientadas. $\mathrm{O}$ autor ainda afirma que seja com as práticas corporais ou com qualquer outro produto, o local onde essa dinâmica acontece possui suas "[...] próprias características e particularidades históricas e culturais que muitas vezes se contradizem com a lógica e os

1 Para fins desse manuscrito o termo "práticas corporais" será compreendido como manifestações da cultura expressas na dimensão corporal, acompanhando o raciocínio de Lazzarotti Filho et al. (2010). Nesse sentido, os termos atividade física e exercício físico são compreendidos como categorias conceituais abrangidas pelas práticas corporais e somente serão mantidos no texto quando os/as autores/as citados assim o fizerem. 
valores trazidos" (p. 19). Por isso, o autor pontua que a mercadoria pode ter um caráter duplo de sua constituição: da mesma forma que a mercadoria atende uma necessidade, existe a possibilidade de se criar uma necessidade para vender um produto.

Para Bracht (2000) o objeto de estudo e da intervenção em Educação Física gira em torno de um olhar pedagógico para compreensão e explicação do movimento em sua objetivação cultural. Portanto, questiona-se como essa intenção pedagógica tem se manifestado no contexto das academias.

Por ora, sabe-se que o ato da docência na Educação Física em sua totalidade é caracterizado por:

\begin{abstract}
[...] possuir natureza própria que advém da inter-relação entre a teoria e prática, inteiramente articulada ao saber e ao fazer por meio da intervenção educativa no âmbito das práticas corporais, da ginástica, dos esportes, das lutas, do jogo, da dança, dentre outras, seja na academia, na escola, na praça, no clube, nos diversos campos de atuação profissional (GOMES, CHAGAS e MASCARENHAS, 2010, p. 183).
\end{abstract}

Tardif (2011 citado por PAIXÃO, CUSTÓDIO e BARROSO, 2016) descreve que a docência é exercida com base em saberes adquiridos pelo docente, podendo ser divididos em três categorias: profissionais, as quais advêm das instituições formadoras de professores, como colégios e faculdades ligadas às ciências da educação; disciplinares, oriundas da tradição cultural, originais de diversos campos do conhecimento, e; curriculares, as quais abarcam os objetivos, conteúdos e métodos definidos por uma instituição de ensino.

Entretanto, custa pontuar que a atuação profissional por si só é responsável também por constituir a identidade docente, ou seja, as relações de ensino aprendizagem as quais o docente possui não só se estabelecem com base no conhecimento acadêmico-profissional o qual o professor tem o contato com conhecimentos teóricos e técnicos (HUBERMAN, 2007). Então, o fazer cotidiano do próprio trabalho torna-se de grande importância, "[...] pois é nesta instância que são aprendidos, produzidos e articulados os saberes práticos essenciais à atuação dos professores ao longo de suas trajetórias profissionais" (PAIXÃO, CUSTÓDIO e BARROSO, 2016, p.286).

Vale ressaltar também que a articulação desses saberes por parte do professor de Educação Física no contexto das academias de ginástica tem sido considerada como possível agente promotor de saúde. O achado é corroborado por Liz et al., (2010) os quais estudaram os motivos de adesão dos praticantes de exercícios físicos em academias e identificaram que boa parte deles se mantinha ativo no programa motivado pelo ideal da saúde.

Entretanto, vale refletir se esse ideal de saúde almejado por esses alunos é parelho ao descrito na VIII Conferência Nacional de Saúde (BRASIL, 1986), como resultante das condições de vida das pessoas, sendo seus determinantes a habitação, moradia, alimentação, lazer, dentre outros. Data-se que essa concepção vai de encontro à perspectiva restrita de saúde que age sinergicamente com a concepção de corpo representado em sua dimensão de objetificação, isto é, compreendido como uma máquina. Tal representação deixa em segundos planos aspectos culturais como imaginário o simbólico e a história e, sendo assim, limita a possibilidades de sentidos dado ao corpo (LUDORF e ORTEGA, 2013). 
Em todo caso, pode-se pressupor que não cabe ao professor de Educação Física trazer à tona o debate relativo a essas diferentes concepções de corpo e saúde. Todavia, aqui se adota a concepção de Paixão, Custódio e Barroso (2016) que consideram, antes de tudo, o profissional como um professor. E sendo um professor, sabe-se que as propostas educativas são caracterizadas por possuir um caráter ideológico, expressado por um conjunto de crenças ou valores que podem estar a favor do status quo, ou contra, numa perspectiva emancipatória (FREIRE, 2004).

Mesmo assim, não só as objetivações culturais dos alunos devem ser levadas em conta para compreender a educação. Segundo Arroyo (2002), o contexto pessoal do professor não deve ser deixado em segundo o plano: a imagem que possui o docente como categoria tem muito a ver com os seus limites materiais e culturais que o cerca, de acordo com a demanda social que lhe é atribuída.

Portanto, visando identificar os possíveis nuances da docência no âmbito contextualizado, o presente estudo traz como objetivo: compreender a percepção do papel de professor para profissionais de Educação Física recém-formados atuantes em academias de ginástica.

\section{MÉTOdo DE PESQUisA}

Trata-se de uma pesquisa descritiva com abordagem qualitativa. Para Triviños (2008), a pesquisa descritiva possui ênfase no conhecer e descrever fatos e fenômenos de determinada realidade, no caso deste estudo os fatos e fenômenos da relacionados ao papel do professor de profissionais recém-formados atuantes em academias de ginástica. A abordagem qualitativa se ancora em Minayo (1994), para a qual afirma se tratar de uma ótica que responde a questões muito particulares, se preocupando com um nível de realidade que não pode ser quantificado.

Trata-se dos resultados principais de um estudo de Iniciação Científica desenvolvido na Universidade Federal de São Paulo e aprovado por seu Comitê de Ética e Pesquisa CAAE $n^{\circ}$ 01504818.7.0000.5505 e todos os voluntários assinaram um Termo de Consentimento Livre e Esclarecido (TCLE).

Participaram do estudo nove profissionais de Educação Física, de ambos os sexos, com faixa etária entre 21 e 29 anos.

Os critérios de inclusão consistiram em:

- Ter concluído a graduação nos últimos 2 anos;

- Atuar em academias de ginástica;

O critério de não inclusão consistiu em:

- Possuir outro vínculo profissional que não seja no âmbito de academias de ginástica.

O recrutamento dos voluntários foi feito em mídias eletrônicas e no site da Universidade... (sob sigilo até o final da avaliação). Na ocasião, foi feito um convite ao estudo, sendo informado o propósito, os critérios de inclusão e o contato dos pesquisadores (e-mail, telefone e aplicativo de conversa).

Como instrumento de coleta de dados utilizou-se a entrevista semiestruturada, que, para Triviños (2008), é um dos principais meios de coleta de dados em pesquisa qualitativa, 
a qual parte de certos questionamentos básicos que interessam à pesquisa. No caso deste estudo, o roteiro de entrevista consistiu em:

1. Em sua opinião, o que é ser professor?

2. Como você entende seu papel de professor em academias de ginástica?

3. Qual é a relação entre à sua formação acadêmica e sua atuação profissional em academias de ginástica?

Entretanto, por limites impostos a um texto como esse só serão analisados os dados referentes às duas primeiras questões.

Todas as entrevistas foram gravadas mediante consentimento dos voluntários e, posteriormente, transcritas para um arquivo eletrônico. A coleta de dados teve a duração de 3 meses e ocorreu entre o período de novembro de 2018 e janeiro de 2019. A análise do conteúdo das respostas dos professores foi feita por categorias não apriorísticas, que, para Campos (2004), emerge totalmente do contexto das respostas.

\section{RESUltados}

Zelando pela preservação do anonimato utilizaremos pseudônimos para identificação dos voluntários. O Quadro 1 e o perfil de atuação no magistério superior de cada voluntário da pesquisa.

Quadro 1 -Perfil dos voluntários

\begin{tabular}{|c|c|c|}
\hline PSEUDÔNIMO & $\begin{array}{c}\text { ANO DE CONCLUS̃̃O DA } \\
\text { GRADUAÇÃO }\end{array}$ & $\begin{array}{c}\text { EXPERIÊNCIA PROFISSIONAL* } \\
\text { EM ACADEMIAS DE GINÁSTICA } \\
\text { (meses) }\end{array}$ \\
\hline Ana & 2017 & 15 \\
\hline Carlos & 2017 & 15 \\
\hline Fernando & 2017 & 24 \\
\hline Marcela & 2018 & 3 \\
\hline Marcos & 2017 & 24 \\
\hline Marta & 2018 & 3 \\
\hline Rafael & 2017 & 24 \\
\hline Renato & 2017 & 15 \\
\hline Silas & 2017 & 21 \\
\hline
\end{tabular}

Fonte: dados da pesquisa.

*Para todos os voluntários essa foi a primeira experiência profissional após formado.

Em relação ao papel do professor, o conjunto de respostas dos voluntários permitiu identificar quatro categorias, a saber:

1. Professor como Transmissor do Conhecimento;

2. Professor como Influenciador;

3. Professor como Aprendiz;

4. Professor como Mediador do Conhecimento. 
Na primeira categoria ("Transmissor do Conhecimento"), as respostas convergiram para um entendimento comum de que a figura docente exerce o papel de repassar conhecimento.

[...] transmitir conhecimento de forma sistematizada ou até mesmo sistematizar algum conhecimento que o aluno já tenha. (MARCOS).

\section{Bom, eu acho que o papel do professor é passar o conhecimento sem viés de confir- mação (RENATO).}

O professor independente do que quer que ele ensine, é isso: passar conhecimento, instruir, ensinar. No nosso caso, professor de educação física, nós temos o papel de ensinar o indivíduo não só uma modalidade ou gesto específico, mas entender seu corpo, como ele funciona e torna-lo melhor, é o que eu passo hoje. (CARLOS)

Ser professor é passar o conhecimento para o aluno de forma que ele compreenda o que está sendo ensinado, seja ensiná-lo na teoria ou na prática, você o fazer entender o que está sendo proposto. (FERNANDO)

Bom, é meio difícil de falar, mas o professor em si, é aquele que ensina, ele passa aquilo que ele sabe (...) (MARTA)

Alguém encarregado de ensinar independente da área que for. (ANA)

Já na categoria "Professor como Influenciador", as respostas foram alusivas ao professor como uma pessoa de referência para os alunos.

Eu diria que $70 \%$ nem imagina o poder que tem com os alunos, assim o quanto a gente é inspiração para os caras, influencia a vida deles. (SILAS)

O professor é aquela pessoa que deve contribuir de forma positiva do aluno, de forma alguma deve fazer algo para gerar um trauma, algo ruim naquele aluno, uma cobrança excessiva ou algo do tipo. (MARCOS)

Então eu acho que o professor é uma referência, o professor é o cara que quando você tem dúvida você chega nele e tenta tirar as dúvidas. (RAFAEL)

O professor forma opiniões, não só em conhecimento, mais ainda a gente né que atua na área de saúde. Também formar opinião sobre o que é o nosso trabalho, como a gente trabalha, as pessoas identificam como o professor é, e levam alguns conhecimentos para o dia o dia. (ANA)

O professor tem que ir além do gostar, mostrar para o aluno seja das escolas ou da academia que você tem um diferencial, mostrar sua experiência de acordo com você aprendeu durante seu percurso seja na graduação ou fora. (MARCELA). 
Na categoria "Professor Aprendiz", as respostas colocaram ênfase na aprendizagem e na troca de conhecimento que ela proporciona.

[...] então eu acho que ser professor é mais ou menos isso, saber ensinar, ter uma didática e aprender com isso e com todos. (MARTA).

[...] é passar esse conhecimento de uma forma que essa pessoa entenda, respeitando as diferenças, as particularidades dessa outra pessoa, desse aluno, para que haja essa troca entre os dois. (MARCOS)

Por fim, a categoria "Professor como Mediador do Conhecimento", presente apenas na resposta de Rafael, mostrou o papel docente como alguém que mostra um caminho de possibilidades ao aluno.

[...] vai te dar o caminho para você responder e ir atrás dessa questão, ou ele até provoca, então às vezes acho que ele tem que dar uma resposta, nem que às vezes seja uma resposta provocativa, não afirmativa, mas uma resposta provocativa. (RAFAEL)

Em relação ao papel do professor em academias de ginástica, os discursos dos voluntários foram interpretados nas seguintes categorias:

1. Professor Conscientizador;

2. Professor Acolhedor;

3. Professor Instrutor;

4. Professor Aprendiz.

Na categoria "Professor Conscientizador" os voluntários compreenderam seu papel de professor na academia na esteira de promover reflexão em seus alunos sobre o que fazem e porque fazem.

Eu busco sempre ensinar eles sobre aquilo que eles estão fazendo, exemplo: estão fazendo um exercício de musculação, aí eu explico o que é aquilo que eles estão fazendo, qual músculo e tal para que ele possa fazer sozinho, eu procuro despertar um pouco da autonomia dele né. (RAFAEL)

[...] você o fazer entender o que está sendo proposto. Por exemplo: por que eu preciso correr tanto, por que eu preciso fazer $3 \times 12$ ? (FERNANDO)

Eles vão tá lá para ter uma aula, mas com a vivência que você vai tendo, com o contato que você vai tendo, você vai instruindo aquela pessoa a estar ciente do meio que ela está entrando. (ANA)

Tento sempre deixar claro essa parte técnica e falar dos benefícios, isso pode fazer com que eles reflitam a respeito. (CARLOS)

[...] porque além de passar o conhecimento tem que se pensar o que aquilo vai gerar na pessoa que você tá atendendo. (MARCOS) 
Passar o conhecimento para o aluno de forma que ele compreenda. (FERNANDO)

Na categoria "Professor Acolhedor", as respostas convergiram para um professor como agente produtor de cuidado, ao qual a capacidade de escuta é essencial para esse tipo de intervenção.

Às vezes o aluno pode pensar: porque treinar sozinho se eu posso pagar alguém para ser cuidado? Todo mundo gosta de ser cuidado, então o trabalho do professor não deixa de ser um cuidado né?!. (RAFAEL)

[...] então você ter a atenção do aluno o tempo que está com ele e o tempo que está se exercitando para poder escutar ele, é fundamental. (FERNANDO)

No estúdio são cinco alunos para dois professores, justamente para você dar uma atenção maior para o cara. Então o público acaba sendo outro, seria um público que já teve experiência com academia e não gostou, justamente por isso, pelo fato de não ter a empatia ou atenção do professor. Você consegue falar com os caras, saber como o cara tá, o estúdio é pequeno então você sempre tem que estar dando feedback para os dois, a atenção é muito mais focada [...]. (SILAS)

Tem duas academias tops do lado então a nossa é uma academia boa, mas o que muda é nosso diferencial, nosso atendimento ao público e a nossa academia vive cheia você pode vir de manhã, de tarde, a noite é uma academia muito família, onde as pessoas se sentem na liberdade, de se expressar, de brincar na academia, de conversar com os professores. (MARCELA)

Já na categoria "Professor Instrutor", as respostas foram ao encontro de um papel como um profissional encarregado de aplicar o conhecimento adquirido.

O professor em si, é aquele que ensina, ele passa aquilo que ele sabe. (MARTA)

Eu tento aplicar o conhecimento que eu tenho. (CARLOS)

Tanto pode ser para você passar o conhecimento para as pessoas que estão a sua volta, tanto quanto você exercitando algo que outras pessoas vão usar como fundamento para trabalhar. (ANA)

Na categoria "Professor como Aprendiz", apenas a voluntária Marta se colocou no plano de alguém que também aprende:

[...] passa aquilo que ele sabe e aprende também muitas coisas. (MARTA)

\section{Discussão}

A experiência dos recém-formados nas academias de ginástica, com exceção de Marcela e Marta, ambas com 3 meses de experiência, encontra-se entre 1 e 2 anos. Para Ber- 
tevello (2006), as academias de ginástica são grandes aceptoras de recém-formados em Educação Física no mercado de trabalho, encontrando eco em nosso estudo.

Sobre o papel do professor é perceptível a relação direta dos discursos contidos nas categorias "Professor Transmissor do Conhecimento" e "Professor Influenciador" à educação bancária descrita por Freire (2013), a qual se manifesta no ato do professor em depositar conhecimento nos alunos e cobra-lhes o rendimento posterior. Nesse sentido, o autor propõe algumas considerações sobre o processo de ensino aprendizagem aliado a esta visão, como:

- O educador é o que educa; os educandos, os que são educados;

- O educador é o que sabe; os educandos os que não sabem;

- O educador é o que pensa; os educandos os pensados;

- O educador é o que diz a palavra; os educandos, os que a escutam docilmente;

- O educador é o que disciplina; os educandos os, os disciplinados;

- O educador é o que opta e prescreve sua opção, os educandos, os que seguem a prescrição;

- O educador é o que atua; os educandos, os que têm a ilusão de que atuam, na atuação do educador;

- O educador escolhe o conteúdo programático, os educandos, jamais ouvidos nessa escolha, se acomodam a ele;

- O educador identifica a autoridade do saber com sua autoridade funcional, que opõe antagonicamente à liberdade dos educandos; estes devem adaptar-se às determinações daquele;

- O educador, finalmente é o sujeito do processo, os educandos, meros objetos (FREIRE, 2013, p.82-83).

Nesse horizonte, a perspectiva é de uma educação tradicional, na qual os processos são estanques e não atentos às demandas dos alunos e seus contextos e há centralidade na figura do professor. Além disso, embora não apareça explicitamente no discurso dos entrevistados, Coelho Filho e Votre (2010) já descreveram que a associação da aparência do professor e seus hábitos podem estar relacionados a uma política de padronização das aulas nas academias de ginástica. Nessa conjuntura, as práticas de ensino aprendizagem perdem protagonismo para necessidade de aparentar esse perfil que funciona como um chamariz, onde:

Essa prática é construída com base nas representações de empresários e usuários. O que tem importância nesse mercado de imagens são a representação do consumidor e o ato de consumir transformado em lucro. Nessa perspectiva, a representação social engendra a prática (COELHO FILHO e VOLTRE, 2010, p.100).

Para Ludorf e Ortega (2013), que analisaram a relação de professores de academias de ginástica com o envelhecimento, o próprio corpo dos professores influencia sua atuação profissional, servindo muitas vezes como cartão de visita. Em nosso estudo isso equivale a compreensão de professor como referência dos alunos.

Por outro lado, os discursos contidos nas categorias "Professor Aprendiz" e "Professor como mediador do conhecimento" englobam perspectivas mais críticas que, em tese, se distanciam da educação bancária. A primeira se encaixa no escopo por considerar o 
educador não como aquele que apenas compartilha informações, mas que faz isso ao passo que é subsidiado pelo conhecimento do educando, contribuindo para a construção mútua da aprendizagem. Ou seja, o educador é caracterizado por refazer constantemente seu ato cognoscente a partir do momento que o educando faz novas cognoscibilidades, ou seja, $\mathrm{o}$ ato de reflexão crítica para com o conhecimento acontece de forma mútua, em diálogo (FREIRE, 2013).

No entanto, a compreensão da docência se mostra tão complexa que, os mesmos três voluntários (Marta, Marcos e Rafael) das categorias citadas no parágrafo anterior possuem, também, um discurso caracterizado pela educação bancária. Isso nos permite afirmar que a troca entre professor e aluno possa ser vertical ou que exista uma hierarquia mantida, perdendo assim a construção mútua de conhecimento. Entretanto, há necessidade de se considerar outra perspectiva, que, distante da educação bancária - compreendendo haver uma distância entre o discurso e a prática pedagógica dos professores -, resultaria no professor como responsável, segundo Freire (2013), por potencializar as relações gnosiológicas: um objeto comum entre educador e educando não deve ser o final de uma relação de vertical de aprendizagem e sim possibilitar novos atos cognoscentes.

Nessa esteira, o aluno desenvolve o pensar autêntico de forma que sua consciência não seja marginalizada. Assim, ao invés de transformar hierarquicamente a mentalidade do aluno, como se o sujeito fosse externo a ela, o docente dá caminhos que possibilitem os educandos modificar sua própria realidade permitindo-os possibilidades de serem seres para si (FREIRE, 2013). Contudo, trata-se aqui de um limite do nosso estudo, que só seria superado caso a observação participante no contexto de prática pedagógica desses voluntários fosse considerada no processo de pesquisa e que outros atores sociais (alunos, colegas de profissão e gestores das academias) pudessem ser ouvidos. Por ora, é possível afirmar a ambiguidade de duas percepções presentes: uma tradicional (centrada no professor) e outra crítica (aberta às demandas dos alunos). Embora seja fato que todos os voluntários tiveram suas respostas interpretadas na ótica da educação tradicional, nos permitindo afirmar que essa percepção foi majoritária.

No que se refere a percepção do papel do professor em academias de ginástica, a análise identificou semelhanças discursivas presentes na questão "O que é ser professor?", por exemplo na categoria "Professor Conscientizador". Podemos interpretar os discursos nessa categoria na perspectiva da transição da curiosidade ingênua para epistemológica, descrita em Freire (2013). Nesse sentido, o autor considera que o docente que compreende os processos de ensino aprendizagem deve estimular o educando a refletir sobre as realidades encontradas pelo mesmo. Só assim o educando passará a aprimorar sua criticidade o que incide na busca por autonomia (FREIRE, 2013).

Sabe-se que boa parte das atividades desenvolvidas em academias engloba os saberes oriundos das ciências naturais, principalmente do treinamento esportivo. Sendo, assim, Gomes (2009) ratifica que os princípios especiais da preparação desportiva, orientados por conhecimentos de cunho biológico, são a proeminência do ato, já que naturalmente esses princípios refletem suas regras específicas.

Contudo, sabendo que a relação que se dá entre professor e aluno é uma relação pedagógica, o autor também considera os princípios gerais ou pedagógicos que se configuram 
(...) na esfera da pedagogia geral, que une os conhecimentos aplicados referentes às regras do ensino e da educação; em outras palavras, são conhecidos pela denominação dos princípios da consciência e da atividade, da intuitividade e da acessibilidade, do caráter sistemático, e etc. Isso é adequado à medida que os princípios desse gênero, elaborados corretamente, reflitam as regras universais do ensino e da educação que permeiam a preparação do atleta (GOMES, 2009, p. 22).

Ou seja, há necessidade, mesmo no ambiente do treinamento esportivo, fazer com que o aluno desenvolva autonomia. Entretanto, são discutíveis quais são os desdobramentos desse diálogo, pois alguns discursos dos voluntários do nosso estudo estão mais alinhados com Freitas (2012), quem afirma que os profissionais de Educação Física em academias de ginástica, esporadicamente, conduzem suas práticas corporais conforme os anseios do aluno. Isso é problemático porque parte dos anseios dos alunos podem estar associados com as características socioeconômicas e do território onde a academia está inserida que, não raro, abarcam um viés midiático e mercadológico que contrariam o ideal de autonomia pressuposto (FREITAS, 2012).

Para Silva, Freitas e Ludorf (2019, p. 106) existem aí duas possíveis abordagens:

[...] a postura mercadológica, na qual há preocupação de se vender os benefícios - principalmente estéticos - das práticas corporais ao cliente; e a de orientação, na qual há preocupação em orientar de maneira "pedagógica" os alunos (grifo dos autores).

Para aos autores, essas abordagens estão longe de serem simplórias, pois: a primeira visão, que mesmo baseando sua intervenção meramente em saberes biomédicos, parece necessitar de um apelo mercadológico, este que deve considerar o contexto de compra e venda de corpos para manter o engajamento de seus alunos nas práticas corporais ofertadas (SILVA, FREITAS e LUDORF, 2019).

Por outro lado, é interessante perceber ainda que uma conscientização ontológica pode resultar também numa maior adesão dos alunos ao programa de práticas corporais. Rabelo e Garcia (2006) sugerem que, quando o educando compreende suas próprias demandas e os respectivos métodos para atingi-las, a aquisição de resultado se torna mais eficiente, visto que a potencialização dos aspectos motivacionais instiga o praticante a se manter ativo em sua prática corporal.

Noutra esteira, os discursos abarcados nessa categoria (Professor Conscientizador) também se assemelham à Silva, Freitas e Ludorf (2019) quando afirmam: alguns professores possuem uma perspectiva mais tradicional, na qual se ensinaria ao aluno caminhos técnicos científicos mais coerentes para se atingir determinados anseios, de outra forma, alguns professores se dispõem a fazer os alunos questionarem seus anseios e direcionar os possíveis caminhos técnicos para atingi-los. Principalmente por fins de produtividade, a primeira conduta tem sido mais difundida, contudo, dados apontam que mesmo imersos nessa perspectiva, professores de Educação Física têm criado estratégias de convencimento para não contrariar os anseios de seus alunos e ainda desmistificar aspectos que os docentes consideram simplistas dentro do espectro biomédico (SILVA, FREITAS e LUDORF, 2019). 
Furtado (2007) discorre mais precisamente sobre esse "mercado", afirmando que o viés mercadológico se desenrola a partir do momento que a academia de ginástica cria e identifica novas necessidades criadas pela sociedade e, para tanto, desenvolvem práticas corporais para atendê-las. Para o autor, essas necessidades permutam em torno da aliança beleza e saúde, que segundo o autor está relacionado a um contexto sócio histórico complexo que, isoladamente, as academias de ginástica não darão conta de satisfazer à demanda desses alunos. Em síntese, é possível afirmar que os discursos constantes na categoria "Professor Conscientizador" revelam a percepção de um professor como responsável pela ação reflexiva junto ao aluno.

Já na categoria "Professor Acolhedor", os entrevistados compreenderam que o professor tem o papel de acolher as demandas dos alunos, a segunda classificação que recebeu maior identificação por parte dos voluntários. Essa postura tem respaldo no que Freire (2004) caracteriza como essencial em uma intervenção relacionada à educação: saber escutar. Para o autor essa atitude é demonstrada pela capacidade de controlar não só a necessidade de dizer a sua palavra, que é um direito, mas também o gosto pessoal, profundamente respeitável, de expressá-la. Nessa perspectiva, se o educador não se propuser a escutar o que o escutado tem a dizer, acaba por esgotar sua capacidade de dizer o que poderia, pois dificilmente terá entendido a real demanda de quem fala (FREIRE, 2004).

Sendo assim, no contexto das academias de ginástica, o professor de Educação Física pode orientar sua prática corporal de acordo com o relato do aluno na perspectiva de apoiá-lo para que vença suas dificuldades na compreensão ou na inteligência do objeto, bem como para que sua curiosidade, compensada e gratificada pelo êxito da compreensão alcançada, seja mantida e assim estimulada a continuar a busca permanente que o processo de conhecer implica.

Ao estudar as principais dificuldades encontradas pelo professor de Educação Física recém-formado ingressante no mercado, Paixão, Custódio e Barroso (2016) perceberam que a maior delas esteve relacionada a atender os objetivos específicos dos alunos em decorrência de suas individualidades e necessidades. Os autores afirmar que $63 \%$ dos voluntários apontaram essa problemática como a maior dificuldade percebida, em oposição a elevada carga de trabalho e a limitação da aparelhagem das academias (PAIXÃO, CUSTÓDIO e BARROSO, 2016).

Os achados de Furtado (2007) discutem essa circunstância e afirmam o eminente potencial das grandes academias de ginástica em tolher as condições de autonomia no modelo de gestão adotado por essas empresas. O viés mercantil das academias de ginástica se aproximava da rigidez fordista por serem desprovidas da influência dos equipamentos tecnológicos e com pouca variedade de serviços, no contexto atual, as grandes academias de ginástica acompanharam as tendências globais da economia dialogando com os princípios toyotistas e adotando a acumulação flexível, marcada por:

[...] um confronto direto com a rigidez do fordismo. Ela se apoia na flexibilidade dos processos de trabalho, dos mercados de trabalho, dos produtos e padrões de consumo. Caracteriza-se pelo surgimento de setores de produção inteiramente novos, novas maneiras de fornecimento de serviços financeiros, novos mercados e, sobretudo, taxas altamente intensificadas de inovação comercial, tecnológica e organizacional (HARVEY, 1996, p. 140 apud FURTADO, 2007, p.72). 
Por isso, é interessante perceber nos relatos como a capacidade de escuta dos professores em alguns voluntários não é interferida quando sua intervenção se dá no âmbito das aulas particulares ou em um estúdio personalizado de treinamento. Logo, percebe-se o quanto as condições de trabalhos reduzem a possibilidade de saber escutar dos professores.

Em Flores (2015), que estudou o planejamento de aulas de Educação Física em academias de Salvador, é possível perceber que muitos docentes são incutidos a aderirem à risca o planejamento de aulas padronizadas fornecidos por empresas. No entanto, nota-se uma preocupação dos professores em relação à explicação dos movimentos em aulas coletivas de ginástica, já que os entrevistados afirmaram realizar pausas ao longo do processo, assim podem ouvir a turma e esclarecer as dúvidas, o que assegura um método de ensino mais concreto (FLORES, 2015). Nesse sentido, a autora destaca ser notório perceber que os professores se empenham no diálogo, mesmo que não seja de forma ideal, já que a produtividade cobrada pode intervir no processo, assim como no nosso estudo. Posto isso, é possível que o dito modelo mercadológico de gestão das práticas corporais presente nas academias de ginástica seja uma das variáveis que podem fazer seus professores a exercer um papel mais próximo da Educação Bancária.

Contudo, o discurso calcado na instrução ("Professor Instrutor") também se fez presente no estudo. No contexto das academias de ginástica interpreta-se que o professor aliado a essa visão educativa conduz sua partir de meras instruções ao aluno em suas práticas corporais, de forma que esse último fique marginalizado de possibilidades mais autênticas e autônomas. Aqui há uma identificação com os pressupostos da educação bancária. Aplicar ou passar o que se sabe nega a dialogicidade do processo ensino-aprendizagem que, compreendido numa mão única, coloca o aluno numa posição inferior ao professor.

Por fim, surgiu ainda o discurso de "Professor Aprendiz", dessa vez somente na voz de Marta. Nessa ótica, parte-se do pressuposto de que o professor quando ensina também aprende (BATISTA, 2004; FREIRE, 2004). Entretanto, Marta também respondeu na direção do professor como instrutor, o que nos coloca diante de um cenário contraditório. Como compreender a troca e a aprendizagem com o aluno (professor aprendiz) quando se deseja passar o conhecimento? Esse é o mesmo limite do qual nos reportamos anteriormente e que só seria possível de ser superado se outros atores fossem ouvidos, o que não ocorreu.

\section{CONSIDERAÇÕES FINAIS}

Os profissionais de Educação Física recém-formados atuantes em academias de ginástica percebem a docência de forma múltipla, sendo capazes de incorporar em seus discursos perspectivas tradicionais e críticas de educação. Todavia, todos os voluntários, em algum momento, tiveram certeza do papel do professor como detentor de conhecimento face à ingenuidade/inferioridade de seus alunos.

Entretanto, tal fato é compreensível por serem recém-formados. Nessa condição, a identidade profissional ainda em construção está passível de vários influenciadores, como o investimento na formação continuada, a condição de trabalho encontrada nas diferentes academias de ginástica, a afinidade com a área do fitness, a remuneração, dentre outros. Para Huberman (2007), há uma colisão dentre os conhecimentos adquiridos durante a gra- 
duação com a realidade do trabalho e o professor deve ajustar isso, o que nem sempre está de acordo com o que o profissional idealiza.

Por isso é que os dados desse estudo devem ser lidos com cautela, pois embora revelem uma percepção de professor predominante em direção à educação tradicional, há um potente flerte com as perspectivas críticas. Nesse sentido, faz-se necessário recorrer à Ceccim (2007) quando traduziu algumas lições de Paulo Freire: os professores devem permanecer pacientemente impacientes. Ou seja, inquietos com a realidade que os cerca. Ora, não poderíamos afirmar ser essa uma das características de todo recém-formado?

Não buscando uma resposta definitiva podemos afirmar que reside aí uma boa pista para a atuação docente em Educação Física no contexto de academias de ginástica. Contudo, é fato que se trata de um ramo em constante ascensão, principalmente no que se refere aos recém-formados. Nesse sentido, assume-se que esclarecer os aspectos que marcam e definem a docência no mundo fitness se mostra pertinente tanto para os profissionais que a constituem quanto para as pessoas que usufruem.

\section{REFERÊNCIAS}

ARROYO, M.G.A. Ofício de Mestre: imagens e autoimagens. 2.ed. Petrópolis: Vozes, 2002.

BATISTA, S.H.S. Aprendizagem, ensino e formação em saúde: das experiências às teorias em construção. In: BATISTA, N.A.; BATISTA, S.H. (Orgs.) Docência em saúde: temas e experiências. São Paulo: Senac, 2004. p.57-71.

BERTEVELLO, G. Academias de ginástica e condicionamento físico - Desenvolvimento. In: DACOSTA, L.P. (Org.). Atlas do esporte no Brasil. Rio de Janeiro: CONF EF, 2006. p.176-177.

BRACHT, V. Educação física \& ciência: cenas de um casamento (in)feliz. Revista Brasileira de Educação Física e Esporte, Campinas, v.22, n. 1, p.53-63, set., 2000.

BRASIL. Ministério da Saúde. Ministério da Previdência e Assistência Social. Relatório Final da VIII Conferência Nacional da Saúde. Brasília, 1986.

CAMPOS, J.G.C. Método de análise de conteúdo: ferramenta para a análise de dados qualitativos no campo da saúde. Revista Brasileira de Enfermagem, Brasília v.5, n.57, p.611614, out., 2004.

CECCIM, R.B. Pacientes impacientes: Paulo Freire. In: BRASIL. Ministério da Saúde. Secretaria de Gestão Estratégia e Participativa. Departamento de Apoio à Gestão Participativa. Caderno de Educação Popular e Saúde. Brasília: Ministério da Saúde, 2007. p.32-45.

COELHO FILHO, C.A.A; VOLTRE, S.J. Imagens da prática profissional em academias de ginástica na cidade do Rio de Janeiro. Revista Brasileira de Ciências do Esporte, Porto Alegre, v. 31, n. 3, p. 95-110, maio, 2010. 
FLORES, A.A. Ginástica em academia: compreensões sobre o planejamento de aulas em Salvador. 2015.92f. Dissertação (Mestrado em Educação) -Universidade Federal da Bahia, Salvador, 2015.

FREIRE, P. Pedagogia do oprimido. 67.ed. São Paulo: Paz e Terra, 2013.

FREIRE, P. Pedagogia da autonomia: saberes necessários à prática educativa. 24ed. São Paulo: Paz e Terra, 2004.

FREITAS, D.C. et al. As práticas corporais nas academias de ginástica: um olhar do professor sobre o corpo fluminense. Revista Brasileira de Ciências do Esporte, Florianópolis, v.33, n.4, p.959-74, out./dez., 2011.

FURTADO, R.P. O não lugar do professor de Educação Física em academias de ginástica. 2007. 188 f. Dissertação (Mestrado em Educação) -Universidade Federal de Goiás, Goiânia, 2007.

GOMES, A. C. Treinamento desportivo: estruturação e periodização. 2.ed. Porto Alegre: Artmed, 2009.

GOMES, I.R.; CHAGAS, R.A; MASCARENHAS, F. A Indústria do fitness, a mercantilização das práticas corporais e o trabalho do professor de Educação Física: o caso Body Systems. Movimento, Porto Alegre, v.16, n. 4, p.169-189, out./dez., 2010.

HARVEY, D. Condição pós-moderna. 6.ed. São Paulo: Loyola, 1996.

HUBERMAN, M. Ciclo de vida profissional dos professores. In: NÓVOA, A. (Org.) Vida de professores. Porto/Portugal: Porto Editora, 2007, p.31-61.

LAZZAROTTI FILHO, A. et al. O termo práticas corporais na literatura científica brasileira e sua repercussão no campo da Educação Física. Movimento, v.16, n.1, p.11-29, jan./ mar., 2010.

LE BRETON, D. Adeus ao corpo: antropologia e sociedade. Campinas: Papirus, 2003.

LIZ, C.M. et al. Aderência à prática de exercícios físicos em academias de ginástica. Motriz, Rio Claro, v.16, n.1, p.181-188, jan./mar., 2010.

LUDORF, S.M.A; ORTEGA, F.J.G. Marcas no corpo, cansaço e experiência: nuances do envelhecer como professor de Educação Física. Interface, Botucatu, v.17, n.46, p. 661675, set., 2013.

MINAYO, M.C.S. Pesquisa social: teoria, método e criatividade. 9.ed. Petrópolis: Vozes, 1994. 
PAIXÃO, J.A; CUSTÓDIO, G.C.C; BARROSO Y.W.S. O processo de aprendizagem do professor de Educação Física atuante em academias de ginástica no início de carreira. Pensar a Prática, Goiânia, v.19, n.2 286-299, abr.jun., 2016.

RABELO, J.A; A.B, GARCIA. Pedagogia e andragogia na sala de musculação. Lécturas, Educación Física y Deportes, Buenos Aires, v.10, n.94, p.1-1, mar., 2006.

SCHERER, A. Educação Física e os mercados de trabalho no Brasil: Quem somos, onde estamos e para onde vamos? In: FIGUEIREDO, Z.C.C. (Org.). Formação profissional em Educação Física e mundo do trabalho. Vitória: Faculdade Salesiana de Vitória, 2005. p. 31-46.

SILVA, A.C; FREITAS, D.C; LUDORF, S.M. A. Profissionais de Educação Física de academias de ginástica do Rio de Janeiro e a pluralidade de concepções de corpo. Revista Brasileira de Ciências do Esporte, Porto Alegre, v. 41, n. 1, p. 102-108, mar., 2019.

TARDIF, M. Saberes docentes e formação profissional. 16. ed. Petrópolis: Vozes, 2011.

TRIVIÑOS, A.N.S. Introdução à Pesquisa em Ciências Sociais: a pesquisa qualitativa em educação. 16.reimp. São Paulo: Atlas, 2008.

\section{DADOS DOS AUTORES}

\section{Jỗo Vitor Cruz}

Graduando em Educação Física. Unifesp - Campus Baixada Santista. Membro estudante do Grupo de Estudo e Pesquisa Sociocultural em Educação Física (GEPSEF). joaovitorcruz8822@gmail.com

\section{Rogério Cruz de Oliveira}

Doutor em Educação Física (Unicamp). Professor do Departamento de Ciências do Movimento Humano da Unifesp - Campus Baixada Santista. Professor do Curso de Educação Física e do Programa de Pós-graduação Interdisciplinar em Ciências da Saúde da Unifesp - Campus Baixada Santista. Líder do Grupo de Estudo e Pesquisa Sociocultural em Educação Física (GEPSEF).rogerio.cruz@unifesp.br

Submetido em: 17-06-2020

Aceito em: 09-07-2021 